\title{
DIE MATE VAN BEVOEGDHEID VAN NUUT-GEKWALIFISEERDE VERPLEEGKUNDIGES NA VOLTOOIING VAN DIE 4-JAAR DIPLOMA KURSUS
}

\author{
HS BLAUWOL, V BROWN, DE HEWETT EN W KOTZE
}

\section{ABSTRACT}

The purpose of this study was to determine the competency of newly qualified nurses practitioners in a curative setting after completion of the 4 Year Diploma Course at Otto du Plessis Nursing College. The respondents evaluated their skills and abilities by completing a questionnaire which was developed by the research committee after consultation with the services.

The need to assess competency comes from the desire to have a relevant curriculum enabling the newly qualified nurse to practice in a variety of health settings at all levels of care. The degree of competency related to practice in a curative setting was selected for particular attention because most newly qualified nurses in the target group were still employed in a curative milieu.

Findings revealed various deficits or inadequacies in competency levels and recommendations were made to adapt the curriculum.

\section{OPSOMMING}

Die doel van hierdie studie was om die bevoegdheid van nuut-gekwalifiseerde verpleegkundiges in ' $n$ kuratiewe milieu te bepaal, nadat hulle die 4 Jaar Diploma Kursus by Otto du Plessis-Verplegingskollege voltooi het. Die respondente het hul eie vaardighede en vermoëns evalueer deur ' $n$ vraelys te voltooi wat deur die navorsingskomitee ontwikkel is na besprekings met die dienste.

Die behoefte om bevoegdheidsevaluasie te bepaal, spruit uit die nodigheid om altyd ' $n$ relevante kurrikulum te hê wat die nuut-gekwalifiseerde verpleegster in staat stel om in enige gesondheidsdiens op enige vlak te kan praktiseer. Die kuratiewe milieu is gekies om die bevoegdheid in die praktyk te evalueer omdat meeste nuut-gekwalifiseerde verpleegkundiges van die studie by kuratiewe instellings werk

Daar is gevind dat daar verskeie tekortkominge in die bevoegdheidsvlakke is en aanbevelings is gemaak vir kurrikulum aanpassings.

die nuut-gekwalifiseerde verpleegkundige is deur middel van semigestruktureerde onderhoude bepaal met betrekking tot:

Die Navorsingskomitee van die Otto du Plessis-Verplegingskollege het besluit om die bevoegdheid van nuut-gekwalifiseerde verpleegkundiges wat die 4-Jaar Diploma Kursus gevolg het, te ondersoek.

Die motivering vir die ondersoek was dat daar uit verskillende oorde kritiek gelewer word op die bevoegdheid van die verpleegkundiges wat die 4-Jaar Diploma Kursus voltooi het.

Die komitee het besluit om ' $n$ opname onder nuut-gekwalifiseerde verpleegkundiges te doen waartydens die betrokkenes hul eie bevoegdheid ten opsigte van hul praktykvoering moes evalueer. As voorbereiding hiervoor is "n opname onder die Senior- en Hoofverpleegkundiges sowel as Verpleeg- diensbestuurders van Tygerberghospitaal gedoen. Die verwagtinge van die diens ten opsigte van * pasiëntsorg (psigo-sosiale vaardighede ingesluit)

* professionalisme

* onderrig

* bestuursvaardighede

Die inligting deur hierdie opname verkry, is gebruik om die vraelys saam te stel waarvolgens die nuut-gekwalifiseerde verpleegkundige haar/sy bevoegdheid ten opsigte van die verwagtinge van die diens evalueer.

\section{PROBLEEM}

Dit is baie belangrik dat die nuutgekwalifiseerde verpleegkundige se bevoegdheid om te praktiseer, evalueer word.
Die dienste spreek dikwels die mening uit dat die produk van die 4Jaar Diploma Kursus nie so bevoeg is om te praktiseer as byvoorbeeld die produk van die vorige 3 en $31 / 2$ jaar Diploma Kursus nie.

Die probleem wat dus aangespreek moet word is om te bepaal of daar werklik " $n$ leemte is in die bevoegdhede van die nuut-gekwalifiseerde verpleegkundige wat die 4-Jaar Diploma Kursus by Otto du Plessis-Verplegingskollege gevolg het.

\section{DOELSTELLING}

Die doelstelling van die studie is om te bepaal of daar enige leemtes, gemeet aan verwagtinge van die diens, in die praktykvoering van die nuut-gekwalifiseerde verpleegkundiges is.

\section{Die doelwitte van die studie is:}

* om te bepaal of die kurrikulum van die 4-Jaar Diploma student by die Otto du Plessis-Verplegings kollege relevant tot die kuratiewe van diensbehoefte instellings soos Tygerberghospitaal is

* om leemtes in die opleidingsprogram te identifiseer

* om na aanleiding van die bevindings, aanbevelings te maak

Aangesien die meeste nuut-gekwalifiseerde verpleegkundiges wel by hierdie of soortgelyke kuratiefgeoriënteerde gesondheidsinrigtings praktiseer, het die komitee besluit om die omvang van die studie tot hierdie area te beperk.

\section{DEFINISIES VAN TERME}

Die begrippe wat in hierdie studie gebruik is, word soos volg gedefinieer:

\section{Vier Jaar Diploma Kursus}

'n Program van onderrig en opleiding, goedgekeur kragtens SARV regulasies 425 van $22 / 02 / 82$ artikel 15 (3) wat lei tot die verwerwing van ' $n$ kwalifikasie wat die houer daarvan die reg verleen tot Registrasie as Verpleegkundige 
(Algemene, Psigiatriese en Gemeenskaps-) en Vroedvrou.

Nuut-gekwalifiseerde verpleegkundige Dit verwys na ' $n$ persoon wat ' $n$ jaar of minder bydie SARV vir die eerste keer as Verpleegkundige (Algemene, Psigiatries en Gemeenskaps-) en Vroedvrou geregistreer is.

\section{Bevoegdheid}

Die uitvoer van veilige en kundige verpleegsorg volgensvoorafbepaalde standaarde en binne die geregistreerde verpleegkundige se bestek van praktyk soos uiteengesit in R2598 van 30 November 1984 soos gewysig.

\section{LITERATUUR OORSIG}

Daar was nie genoegsame inligting beskikbaar oor die onderwerp met betrekking tot Suid-Afrika nie.

Volgens Troskie (1993 : 50) word die bevoegdheid van die nuut-gekwalifiseerde verpleegkundige om as geregistreerde verpleegkundige te praktiseer, bevraagteken. Sy het bevind dat die bevoegdheid van die nuut-gekwalifiseerde verpleegkundige nie beduidend deur plasing en oriëntering beïnvloed word nie. Die noodsaaklikheid van voldoende begeleiding an die nuut-gekwalifiseerde verpleegkundige het duidelik na vore gekom.

Onderhoude is gevoer met die Senior-, Hoofverpleegkundiges en Verpleegdiensbestuurders van die Tygerberghospitaal. Semigestruktureerde vraelyste is gebruik om die verwagtinge van die diens ten opsigte van die praktykvaardigheid van nuut-gekwalifiseerde verpleegkundiges te bepaal.

\section{METODOLOGIE}

\section{Navorsingsontwerp}

'n Opname is gedoen deur middel van 'n vraelys. Die doel van die opname was om inligting te verkry om sodoende sekere aanbevelings te kan maak.

\section{Navorsingsinstrument}

'n Gestruktureerde vraelys is ontwerp, maar plek is ook gelaat vir die lewer van kommentaar. Die respondente is in die dekkende brief aangemoedig om wel kommentaar te lewer.

Die vraelys is aan respondente gepos en 'n gefrankeerde koevert is ingesluit.

Die vraelys het uit die volgende afdelings bestaan:

\section{- algemene inligting}

\section{Bevoegdheidsevaluering:}

- pasiëntsorg

- professionalisme

- onderrig

- bestuursvaardighede

UITEENSETTING VAN ITEMS

\begin{tabular}{|c|c|}
\hline ITEMS & $\begin{array}{l}\text { \% Respondente wat } \\
\text { dikwels of totaal } \\
\text { onbevoeg voel }\end{array}$ \\
\hline \multicolumn{2}{|l|}{ PASIËNTSORG } \\
\hline $\begin{array}{l}\text { Interpretasie van laboratoriumuitslae } \\
\text { en daaropvolgende toepaslike optrede }\end{array}$ & 39 \\
\hline Vog en medikasieberekeninge: Pediatrie & 23 \\
\hline Hantering van sentrale veneuse druklyn & 18 \\
\hline Hantering van naasbestaandes na ' $n$ sterfgeval & 14 \\
\hline \multicolumn{2}{|l|}{ PROFESSIONALISME } \\
\hline Hantering van arbeidsonrus & 23 \\
\hline \multicolumn{2}{|l|}{ ONDERRIG } \\
\hline Beplanning en implementering van onderrigplan vir afdeling & 14 \\
\hline \multicolumn{2}{|l|}{ BESTUURSVAARDIGHEDE } \\
\hline Merietebepaling en opstel van verslae & 25 \\
\hline Afkeur van voorraad & 18 \\
\hline Bestel van voorraad & 12 \\
\hline
\end{tabular}

Die respondente moes hul eie bevoegdheid te opsigte van situasies in elk van bogenoemde afdelings evalueer en op ' $n$ skaal van $1-5$ plaas.

\section{$1=$ totaal onbevoeg/onveilig}

$5=$ volkome bevoeg/veilig

\section{Teikengroep}

Die teikengroep was die 4-Jaar Diploma Kursus studente wat in Desember 1993 en in Desember 1994 hul opleiding by die Otto du Plessis-Verplegingskollege voltooi het. ' $n$ Total van 101 vraelyste is uitgestuur en 44 voltooide vraelyste is terugontvang, ' $n$ respons van $43,6 \%$.

\section{Data verwerking}

Daar is om slegs die response 1 en 2 op die skaal te analiseer. Die respons 1 was voel totaal onbevoeg en 2 voel dikwels onbevoeg.

Hierdie response is in persentasies verwerk.

Daar is ook om alle kommentaar by die verskillende onderafdelings op te som.

\section{BEVINDINGS}

Itemontleding

Slegs items waar $10 \%$ of meer van respondente dikwels of totaal onbevoeg gevoel het is as relevant tot hierdie studie beskou.

\section{Opsomming van kommentaar}

Die opsomming van die kommentaar het die volgende aspekte uitgelig:

Respondente is van mening dat hul kennis van farmakologie uitgebrei moet word. Hulle versoek dat daar tydens hul vierde jaar van opleiding meer aandag aan binneaarse terapie gegee moet word.
Die tyd en nie die kennis ontbreek om pasiënte effektief ten opsigte van psigososiale probleme te ondersteun. Die hantering van die naasbestaandes (veral as dit ' $n$ groot groep is) van 'n sterfgeval bly ' $n$ probleem.

'n Groot leemte ten opsigte van die interpretasie van laboratoriumuitslae is geidentifiseer. Respondente noem dat hulle nie genoegsaam tydens opleiding daarmee te doen kry nie en dat selfs hul kennis van normale waardes ontbreek.

Vaardighede (ander as die waarvoor in die vraelys voorsiening gemaak is) wat ontbreek volgens sommige respondente se kommentaar is: kateterisering van mans-pasiënte, hantering van stuitverlossings, in werking stel van binneaarse infusies.

Respondente noem dat hulle graag meer geleentheid sou wou hê om as student bevel van in saal te neem. Hulle noem dat as nuut-gekwalifiseerde verpleegkundiges word hul professionele status nie deur almal, en veral nie deur die verpleegstudente, herken nie.

Ten opsigte van hul onderrigfunksie voel die respondente dat hulle nog nie genoeg ervaring het om " $n$ onderrigplan vir ' $n$ afdeling te ontwerp nie. Hulle is wel in staat om onderrig aan pasiënte en studentverpleegkundiges te gee.

Die respondente noem dat die praktyk rakende aspekte soos drogery beheer nie aan die kriteria daargestel tydens opleiding voldoen nie Hierdie is veral die geval in privaat hospitale.

'n Algemene kommentaar rakende die bestuur van voorraad is dat daar min geleentheid geskep word om tydens opleiding aktief daarby betrokke te wees. Respondente voel oor die algemeen onbevoeg of "te junior" om te delegeer of te dissiplineer. 


\section{GEVOLGTREKKINGS}

Leemtes ten opsigte van pasiëntsorg

Interpretasie van laboratoriumuitslae

Die leemte wat mees dikwels deur die respondente ten opsigte van hul bevoegdhede geïdentifiseer is, is die onvermoë om laboratoriumuitslae korrek te interpreteer en toepaslik daarvolgens op te tree.

Alhoewel 'n studentverpleegkundige seide direk betrokke is by die interpreteer van laboratoriumuitslae, blyk dit dat dit wel van haar as geregistreerde verpleegkundige verwag word. Sy moet in staat wees om uitslae te interpreteer en toepaslik op te tree.

Vog en medikasie berekeninge: Pediatrie ' $n$ Leemte geïdentifiseer deur die respondente is die berekeninge rondom medikasie, binneaarse en orale vog veral in pediatriese afdelings.

Hantering van ' $n$ sentrale veneuse druklyn Die bekwame hantering van ' $n$ sentrale druklyn word ook as in leemte deur respondente aangedui. Tydens hul opleiding werk studentverpleegkundiges nie in intensiewe eenhede nie en kom dus weinig in aanraking met sentrale veneuse druklyne.

Hantering van naasbestaandes na ' $n$ sterfgeval Dit is ook 'n probleem vir meer as $10 \%$ van die respondente. Dit blyk dat hierdie sensitiewe aangeleentheid eerder deur meer senior personeel hanteer word.

\section{Pasiënte met psigiatriese probleme}

Ten spyte van die feit dat die student amper ses maande in psigiatriese afdelings geplaas word, is die herkenning en hantering van pasiënte met psigiatriese afwykings ' $n$ probleem. Dit wil voorkom asof die nuut-gekwalifiseerde verpleegkundige geneig is om pasiënte te kompartementaliseer en dus nie haar kennis met haar praktyk integreer nie. Dit mag wees dat ses maande blootstelling aan psigiatriese verpleegkunde onvoldoende is om die student genoegsaam toe te rus vir die hantering van sodanige pasiënte.

\section{Leemtes ten opsigte van professionalisme} Hantering van arbeidsonnus $23 \%$ van die respondente voel onbevoeg om arbeidsonrus te hanteer. Arbeidsonrus is tans aan die toeneem en tot onlangs is daar nie pertinent in die kurrikulum voorsiening vir die hantering daarvan gemaak nie.

\section{Leemtes ten opsigte van onderrig}

Beplanning van ' $n$ onderrigprogram - Meer as $10 \%$ van die respondente voel onbevoeg om ' $n$ onderrigprogram vir ' $n$ afdeling te beplan en te implementeer. Hulle ervaar weerstand wanneer hulle as "nuwe" personeel ' $n$ onderrigprogram wil implementeer en is ook van meing dat hulle nog te onervare is. Werksdruk word as ' $\mathrm{n}$ rede vir die nie-implementering van " $n$ onderrigprogram aangevoer.
Leemtes ten opsigte van bestuursvaardighede Meer as $10 \%$ van die respondente voel onbevoeg met betrekking tot merietebepalings en die bestel en afkeur van voorrade. Dit blyk uit die kommentaar dat studentverpleegkundiges weinig die geleentheid kry om voorraad te bestuur.

\section{AANBEVELINGS}

\section{Interpretasie van laboratoriumuitslae}

Die komitee is van mening dat hierdie probleem dringend aangespreek moet word. Die nuut-gekwalifiseerde verpleegkundige voel onveilig en blootgestel omdat sy nie in staat is om laboratoriumuitslae te interpreteer en toepaslik daarvolgens op te tree nie.

* Studente moet deeglik en deurlopend onderrig word in die normale waardes van die meer algemene ondersoeke.

* Laboratoriumuitslae moet meer spesifiek in al vier opleidingsjare as onderrighulpmiddel gebruik word. Praktykbegeleiers moet deurentyd die pasiënt se vordering in verband bring met laboratoriumuitslae.

* Kennis en insig in die interpretasie van laboratoriumuitslae en daaropvolgende toepaslike optrede behoort gereeld en op 'n geintegreerde wyse geëvalueer te word.

Vog en medikasie berekeninge: Pediatrie Studente wat nie standerd tien wiskunde het nie moet verplig word om ' $n$ basiese rekenkunde ondersteuningskursus te deurloop in hulle eerstejaar van opleiding. Dit sal die student in staat stel om daardie vaardig hede benodig vir die berekening van vog en medikasie te bekom. Sodanige vaardighede moet gereeld versterk en geëvalueer word.

\section{Hantering van sentrale veneuse druklyn}

Die komitee is van mening dat die nuut-gekwalifiseerde verpleegkundige wel hierdie vaardigheid moet bemeester het. Daar word kennis geneem dat studente nie in intensiewe eenhede geplaas word nie en dus $\mathrm{min}$ oefening in die gebruik van sentrale veneuse druklyne kry. Dit word dus aanbeveel dat studente deur middel van simulasie hierdie vaardigheid aanleer en dat dit gereeld versterk word sodat hulle vertroud is met die prosedure na afloop van hul opleiding.

Hantering van naasbestaandes na 'n sterfgeval

Die gesprek rondom die hantering van die sterwende pasiënt, wat tans veral in die eerstejaar van opleiding geskied, moet in die daaropvolgende jaar voortgesit word. Hierdie gesprekvoering behoort onder andere geleentheid te bied vir studente om in groepsverband hul ervarings, probleme en kwellinge ten opsigte van sterwensbegeleiding te deel.

Die dienste moet egter kennis neem dat vaardigheid op hierdie gebied afhanklik van 'n ontwikkelingsproses is en dit wenslik is om voortdurend hierdie leemte deur byvoorbeeld, indiensopleidingsprogramme, aan te spreek.

\section{Pasiënte met psigiatriese probleme}

Studentverpleegkundiges moet aangemoedig word om tydens hul plasing in die algemene en verloskundige afdelings die pasiënt in sy totaliteit te benader. Dit impliseer dat dieselfde benadering deur almal betrokke by studentopleiding gevolg moet word.

\section{Hantering van arbeidsonrus}

Die hantering van arbeidsonrus en insig in arbeidswetgewing moet in die kumikulum beklemtoon word. Dit moet "n praktiese aanslag hê bv. rolspel, groepwerk en simulasies.

\section{Beplanning van ' $n$ onderrigprogram}

Daar word aanbeveel dat die student tydens haar opleiding die opdrag kry om in een van die afdelings ' $n$ onderrigprogram vir een week op te stel en ' $n$ aktiewe bydrae by die aanbieding daarvan te lewer.

Leemtes ten opsigte van bestuursvaardighede Geleenthede moet geskep word gedurende die opleiding vir die skryf van merietebepalings en die aktiewe betrokkenheid by die bestel en afkeur van voorraad. Kliniese personeel behoort hierdie as ' $n$ belangrike aspek van hul onderrigtaak te beskou.

\section{BEPERKINGS VAN DIE STUDIE}

Die feit dat die studie beperk was tot kuratiewe instellings het tot gevolg dat daar nie bepaal kan word hoe die verpleegkundiges in die gemeenskap funksioneer nie.

\section{AANBEVELINGS VIR VERDERE NAVORSING}

Dit word aanbeveel dat hierdie studie uitgebrei word na gemeenskapsdienste veral met die oog op herkurrikulering volgens die riglyne van die gesondheidsplan.

\section{SAMEVATTING}

Dit is duidelik dat die bevoegdheid van die nuutgekwalifiseerde verpleegkundige afhanklik is van die insette van beide die onderrig-instansie sowel as die opleidingsfasiliteite.

Sekere leemtes is bepaal wat in die bestaande kurrikulum aangespreek moet word. Ander leemtes wat ervaar word, soos probleme om die naasbestaandes van sterwendes te ondersteun, kan beskou word as deel van 'n professionele ontwikkelingsproses wat geensins voltooi is teen die einde van die opleiding nie.

Die waarde van die doeltreffende begeleiding van die nuut-gekwalifiseerde verpleegkundiges, nie hier ondersoek nie, kan ook nie onderskat word nie.

Ten slotte: Die sukses en relevansie van enige onderrigprogram word bevorder deur gereelde 
navorsing en programevaluasie en die komitee is van mening dat soortgelyke studies baie waardevolle inligting kan oplewer.

\section{VERWYSINGS}

Brink, H.I.L. (1993). Validity and reliability in qualitative research. Curationis. 16,(2), 35 -38.

Troskie, R. (1993). Critical evaluation of the newly qualified nurses' competency to practice. Part 1 and 2. Curationis. 16.(3), $50-61$

\section{ERKENNINGS}

Ons erken met dank die bydrae van die volgende personeel:

- Verpleegpersoneel van Tygerberg-Hospitaal met wie onderhoude gevoer is tydens fase 1 van die projek.

- Personeel van Otto du Plessis-Verplegingskollege wat behulpsaam was met bogenoemde onderhoude.
HS Blauwol - Senior dosent Hons. B Verpleegkunde Verpleegonderwys en Geemeenskapsverpleegkunde, Diploma in Verloskunde.

Diploma in Verpleegadministrasie

$\checkmark$ Brown - Senior dosent Tans besig met B.A. CUR

DE Hewett - Senior dosent

B.A. Hons Sielkunde

B.A. CUR (Onderwys en

Gemeenskapsverpleegkunde

Diploma in Algemene Verpleegkunde Diploma in Verloskunde

Diploma in Verpleegadministrasie

W Kotze - Senior prinsipale

B. Cur. Hon (Verpleegonderuys) OTTO DU

PLESSIS-VERPLEGINGSKOLLEGE 